\title{
LETRAMENTO ESCOLAR E IDENTIDADE: DISCUTINDO A PRÁTICA DOCENTE COM TEXTOS
}

\author{
Carla Luzia Carneiro Borges
}

RESUMO: Discute-se a prática docente com textos, refletindo sobre seu impacto na construção de identidades na sala de aula. O trabalho fundamenta-se nas noções de letramento dos Novos Estudos do Letramento (Street, 1984); de identidade (Hall, 2003); de texto/discurso (Bakhtin, 1997; 2004) e de leitura/escritura (De Certeau, 2008a; 2008b). Proponho um exercício de leitura de produções escritas de duas escolas Riachão do Jacuípe/Ba, as quais passam por formação continuada de professores com base na Pedagogia de Paulo Freire (projeto CAT/UEFS/MOC).

PALAVRAS-CHAVE: Letramento. Identidade. Texto/discurso.

ABSTRACT: This paper discusses the practice of teaching texts, reflecting on its impact on the construction of identities in the classroom. The work is based on the concepts of literacy of the New Literacy Studies (Street, 1984); identity (Hall, 2003); text / discourse (Bakhtin, 1997, 2004) and reading / writing (De Certeau, 2008a, 2008b). I propose an exercise in reading written productions of two schools of Riachão Jacuípe / $\mathrm{Ba}$, which undergo continuous training of teachers based on the pedagogy of Paulo Freire (CAT project / UEFS / MOC).

KEYWORDS: Literacy. Identity. Text/speech.

\section{INTRODUÇÃO}

Com este artigo, proponho uma discussão sobre como a prática docente com textos contribui para a construção de identidades na sala de aula. $\mathrm{O}$ olhar que proponho para o letramento, portanto, está fundamentado em determinada concepção de texto e de gênero. Tomo o texto como um espaço de constituição de sujeitos em diálogo na sociedade, consequentemente como espaço de construção de identidades de natureza fluida, em constantes deslocamentos. O texto, portanto, é visto não como uma unidade homogênea, estática, com forma cristalizada, mas um texto em movimento, em rede, cada um funcionando num contínuo dialógico. Esta concepção do texto possibilita pensar que não somente as práticas escritas constituem texto, mas também as práticas orais e não-verbais que circulam socialmente, sempre em rede, em diálogo. 
O letramento, portanto, refere-se ao conjunto das práticas (não somente escritas) às quais os sujeitos estão submetidos e movem-se de modo a produzir textos, o que significa se posicionar nesse contínuo dialógico, bem como ler os textos em circulação, retextualizando-os, (in) subordinando-se a eles. O letramento corresponde a esta dinâmica, visão que se fundamenta na perspectiva bakhtiniana de texto/discurso (1997; 2004), nos Novos Estudos do Letramento (Street, 1984) e soma-se à noção de escritura e de leitura dos Estudos Culturais, na visão de De Certeau (2008a; 2008b).

Proponho uma reflexão acerca do letramento escolar que é realidade num espaço de educação do campo do município de Riachão do Jacuípe. Trata-se de um espaço de formação continuada de professores que tem como base a pedagogia freireana, por isso tem como princípios norteadores 'conhecer', 'analisar' e 'transformar' o espaço no qual a escola está inserida. Meu olhar está para como o texto é colocado, qual o seu lugar como espaço de constituição dos sujeitos em meio aos multiletramentos com os quais está em diálogo.

A relação letramento e identidade favorece uma discussão teórica importante para a compreensão das práticas textuais da linguagem como espaço de produção de conhecimento em diálogo com as culturas e espaço de entendimento do caráter fluido, heterogêneo das identidades.

\section{LETRAMENTO, TEXTO E GÊNERO: DISCUTINDO O CONTÍNUO}

\section{DIALÓGICO}

Assumo a noção de letramento dos Novos Estudos do Letramento (Street,1984) que já é amplamente divulgada no Brasil e coincide com minhas preocupações e modos de ver as práticas com leitura e escrita na escola e fora dela, mas o estudo do letramento ainda requer um olhar para as práticas escolares e não-escolares para dar conta de elementos que me ajudem a pensar no contínuo dialógico que é base da sociedade e da prática textual que naturalmente se dá em rede na sociedade, por suas tessituras, encontros e desencontros, transições, diásporas (Hall, 2006). A esta noção, relaciono a visão de cotidiano de De Certeau que imprime um olhar para os textos em cadeia, quando considera a escritura como uma prática não-cotidiana, de uma ordem diferente da que vive o homem ordinário. Interpreto a escritura, portanto, como um espaço em 
que relações de poder se instauram e que somente podem ser enfrentadas pelas táticas Inventadas ${ }^{1}$ no cotidiano.

Procuro relacionar as posições de Bakhtin (1997) e de De Certeau (2008a; 2008b), acerca do texto/escritura, com dados coletados recentemente em duas escolas da zona rural de Riachão do Jacuípe, município baiano localizado a aproximadamente 60 km de Feira de Santana, no intuito de apresentar a compreensão do objeto texto na realidade pesquisada. As questões/noções advindas de Bakhtin já vêm sendo consideradas em meu trabalho de pesquisa desde 2009. Venho considerando a noção de dialogia e de gêneros do discurso como fundamentais para a compreensão do trabalho com texto no processo ensino-aprendizagem. A essas noções, venho associando as discussões sobre letramento (STREET, 1984; KLEIMAN, 2003 [1995]). As reflexões feitas por De Certeau, acerca dos modos de fazer e das práticas escriturísticas, são mais recentes em meus estudos e são responsáveis, em grande parte, pela discussão sobre a noção de texto que venho compartilhando em grupos de estudo na UEFS e na UFBA ${ }^{2}$.

O espaço do letramento escolar, o qual se volta para as práticas escriturísticas predominantemente, de certa forma nega a construção das identidades, reforçando ações homogeneizadoras com leitura e produção de textos. O texto, ao invés de ser visto como espaço de constituição e diálogo das culturas e identidades, consequentemente, passa a ser espaço de manutenção de uma ordem, de submissão dos sujeitos às ideologias dominantes. Neste estudo, discuto o espaço escolar de pesquisa como um espaço que fica entre a submissão às escrituras consagradas pela escola e a tentativa de transformação do espaço de origem, pelas leituras possíveis.

Retomo a concepção de texto proposta por Bakhtin (2004 [1999]) e Bakhtin (1997), vinculada às práticas sócio-comunicativas com oralidade e escrita, bem como retomo e reforço uma discussão do autor que considera o texto não somente verbal, o que venho ampliando com a discussão de texto/escritura de De Certeau (2008), autor que tem um olhar para o cotidiano e, consequentemente, para as inscrições textuais que se efetivam inclusive no próprio corpo. Por fim, defendo o texto em sua natureza dialógica e cultural. Sempre que me refiro à noção de texto, destaco que De Certeau (2008a) dedica um capítulo às caminhadas pela cidade, que em sua vista panorâmica vê-

\footnotetext{
${ }^{1}$ Usarei 'Inventadas', com letra maiúscula, para me referir à invenção do cotidiano de que fala De Certeau.

${ }^{2}$ Universidade Federal da Bahia.
} 
se "a imensa texturologia", onde, mais embaixo, vivem "os praticantes ordinários da cidade". O leitor encontra-se numa leitura que transcende o texto escrito e passa a ler uma cena urbana, tendo a dimensão de uma natureza diferenciada do texto. A cidade é o grande texto do qual se pode aproximar e ler de perto as redes de relação mais sutis, uma leitura do mundo e do homem ordinário, em constituição de sua história. Descreve o autor (2008a:171):

Tudo se passa como se uma espécie de cegueira caracterizasse as práticas organizadoras da cidade habitada. As redes dessas escrituras avançando e entrecruzando-se compõem uma história múltipla, sem autor, nem espectador, formada em fragmentos de trajetórias e em alterações de espaços (...)

Trata-se de uma vida/uma história que é (ou se constitui) texto. As relações são escritas, as histórias são constituídas numa dimensão não conhecida, não projetada por um olhar desatento ("Escapando às totalizações imaginárias do olhar, existe uma estranheza do cotidiano que não vem à superfície, ou cuja superfície é somente um limite avançado, um limite que se destaca sobre o visível", Certeau, 2008a: 172). Essa compreensão de escritura/leitura de De Certeau provocou uma situação de desequilíbrio na concepção de texto que até então me acompanha(va?). O texto passou a ter uma dimensão bem mais ampla, assim como minha visão do que é fazer história, não mais limitada a passado e acervos antigos, mas construída e documentada pelos modos de fazer diversos, que são registrados diariamente. Uma dimensão do homem e de seu fazer história cotidianamente me fez vislumbrar também novas possibilidades de entender o fazer textual, de analisar o impacto das práticas escriturísticas e o papel da leitura nesse contexto.

Uma discussão sobre linguagem, em sua dimensão cultural seria uma exigência cada vez maior para a compreensão desse olhar para o texto. Para Bakhtin, "a língua existe não por si mesma, mas somente em conjunção com a estrutura individual de uma enunciação concreta. É apenas através da enunciação que a língua toma contato com a comunicação, imbui-se do seu poder vital e torna-se uma realidade. (...)" (BAKHTIN, 2004[1999]:154). O texto, então, seria essa construção enunciativa concreta, situada e em constante diálogo com a realidade. A discussão do autor acerca dos gêneros discursivos também reforça que o texto se faz presente e se constitui socialmente e tem uma natureza de transitar por espaços diferenciados. "Todas as esferas da atividade 
humana, por mais variadas que sejam, estão sempre relacionadas com a utilização da língua.” (BAKHTIN, 1997:279). Essa é a base da noção de gêneros trazida pelo autor e tem impacto sobre a noção de texto em sua natureza multifacetada, heterogênea, pois os gêneros são "tipos relativamente estáveis de enunciados". É sobre essa concepção que o autor enfatiza a variedade dos gêneros, ainda que se limite aos gêneros orais e escritos. Atualmente, outros gêneros, em outras modalidades de linguagem, estão sendo evidenciados, vinculados a questões acadêmicas, políticas e/ou educacionais.

A noção de gêneros do discurso de Bakhtin, em sua natureza primária ou secundária, simples e complexa, desperta para os lugares onde os textos são produzidos, ou pelo menos onde se iniciam, pois os gêneros caracterizam-se por uma relativa estabilidade, o que abre as brechas para a compreensão do texto em rede, que possibilita o diálogo de culturas e de identidades. Os gêneros vinculam-se aos espaços de origem, mas não estão fadados a eles. Os textos circulam, transitam, transfiguram-se graças às leituras a que estão submetidos. Esta é a natureza diaspórica do texto, consequentemente, isso reflete na constituição dos sujeitos e de suas identidades.

\section{LETRAMENTO ESCOLAR E IDENTIDADES: COMO LIDAR COM A}

\section{FLUIDEZ}

Neste item, procuro fazer uma reflexão sobre como o letramento escolar dá conta de questões identitárias, considerando o caráter fluido das identidades. No espaço escolar, culturas estão em diálogo, pois os sujeitos transitam por diferentes origens, crenças, espaços. Hall (2006:26-27) ressalta o seguinte: “(...) Na situação da diáspora, as identidades se tornam múltiplas”. Exatamente pela situação de confronto das diferenças, as identidades vão se constituindo sempre na posição de meio, de hífen, multifacetada, heterogênea, escorregadia. Sobre a diáspora, Hall esclarece:

O conceito fechado de diáspora se apóia sobre uma concepção binária de diferença. Está fundado sobre a construção de uma fronteira de exclusão e depende da construção de um "Outro" e de uma oposição rígida entre o dentro e o fora. Porém as configurações sincretizadas da indentidade cultural caribenha requerem a noção derridiana de différance - uma diferença que não funciona através de binarismos, fronteiras veladas que não separem finalmente, mas são também places de passage, e significados que são posicionais e relacionais, 
sempre em deslize ao longo de um espectro sem começo nem fim. (HALL, 2006, p. 32-33)

A diáspora, portanto, é vista como espaços de passagem e significados que não são únicos, fixos, rígidos, mas variam conforme sua posição, em relação ao Outro. Tomo esta noção da identidade diaspórica, num momento da sociedade voltada também para o virtual, sociedade que é espaço de produção de textos em rede, multimodais e por que não dizer, de natureza diaspórica. O texto e a leitura, então, estão sempre de passagem, em deslize pelos lugares, em circulação. A escola deve se dar conta disso para compreender a constituição dos sujeitos em transição. Nestes meios de caminho, o aluno que "ambula", inclusive pelo espaço virtual, lê e interpreta mundos, pessoas, constrói representações, submete-se a estratégias e as enfrenta, usando táticas diversas (De CERTEAU).

Retomo, então, a pergunta que subjaz ao título deste item: como a escola lida com esta fluidez dos sujeitos, dos textos/discursos e leituras, bem como das identidades na sala de aula. Esta consideração exige uma pedagogia diferenciada, no mínimo, que possibilite a diversidade de textos, de leituras e interpretações; exige um professor sensível às culturas, às diferenças entre seus alunos e entre sua classe e outras, entre sua comunidade de origem e outros espaços de produção de conhecimento. Este modo de lidar com o letramento na escola exige um olhar para além da sala de aula, que se pense no contínuo dos textos, dos gêneros que circulam e que afetam o fazer docente. Mas como isso pode ser feito? O professor, como agente principal do letramento escolar, precisa dispor de uma sensibilidade, algo que parece pouco palpável, mas se traduz por uma pedagogia que considere os seguintes fatores: 1) a heterogeneidade de sua classe; 2) a diversidade de gêneros que circulam dentro e fora da escola; 3) a natureza transitória/diaspórica dos textos que fazem sentido em rede; 4) a natureza discursiva dos textos, que estão submetidos às estratégias de poder, às ideologias dominantes; 5) a natureza fluida das identidades dos sujeitos-alunos que são afetados pelas redes sociais/culurais (inclusive virtuais).

Tudo isso exige práticas de leitura e produção de textos criativas e críticas, que promovam reflexões sobre a condição dos ditos autores de textos, das temáticas discutidas nos diversos gêneros: que gêneros são produzidos e por quem? Em que espaços? O que fazem circular como ideologia na sociedade e em que isso afeta nossas identidades? Que características formais e funcionais têm os textos e quais suas 
condições de produção e de circulação? Com que textos eles tecem rede para que façam sentido na sociedade diversa, atravessada por relações de poder? São questões basilares de uma pedagogia que considere o letramento como lugar de compreensão das identidades.

\section{LETRAMENTO ESCOLAR E IDENTIDADES: UMA EXPERIÊNCIA DE}

\section{LEITURA DE TEXTOS ESCOLARES}

Com as preocupações já mencionadas acerca do modo como o texto estava sendo considerado na escola, num ambiente de formação continuada de professores da rede pública de Riachão do Jacuípe/Ba, pude vivenciar círculos de leitura em duas escolas da zona rural do município que me deram elementos para refletir sobre como o letramento escolar pode dialogar com outras práticas de letramento e possibilitar a compreensão das identidades locais em transição na sociedade.

A realidade pesquisada refere-se a duas escolas cujos professores recebem orientação do Projeto CAT (Conhecer, Analisar e Transformar) da universidade na qual sou professora. Os princípios norteadores estão fundamentados na pedagogia de Paulo Freire, como se pode ver na sigla Conhecer, Analisar e Transformar. Ou seja, os professores são orientados a estimular os alunos a conhecerem sua comunidade, analisar as informações trazidas para a sala e propor o que for preciso para sua melhoria. Os professores participam da construção de uma ficha pedagógica que deve ser seguida em sala, com ajustes necessários conforme cada turma.

Em conjunto com coordenadores e equipe de assessoria do CAT, os professores constroem a ficha pedagógica que é dividida em três momentos, os quais coincidem com os princípios norteadores da formação. $\mathrm{Na}$ etapa do Conhecer, são feitas as perguntas que irão ser feitas à comunidade sobre o tema da ficha, definido por unidade. $\mathrm{Na}$ etapa do analisar, os alunos com seu professor discutem as respostas, numa tentativa de analisar a realidade. Na terceira e última etapa, do Transformar, a turma propõe ações de melhoria para a comunidade e a escola, apresentando suas reivindicações à prefeitura no momento chamado de Devolução. Trata-se de um momento importante, que atrai toda a comunidade escolar e familiares dos alunos para socialização dos trabalhos realizados ao longo das unidades de estudo, quando as reivindicações são 
feitas ao prefeito da cidade, o qual é um dos convidados do evento. Este é um momento importante, uma culminância das ações do Projeto CAT na escola, bem como das ações dos professores e seus alunos, etapa representativa do Transformar.

A seguir, apresento algumas produções coletivas realizadas nas aulas, nas duas escolas pesquisadas, para discutir como se dá o letramento dos alunos e de que modo reflete a construção das identidades e considera seu caráter fluido. A produção a seguir trata da história de criação das comunidades de origem dos alunos de cada professor: Comunidade Baixa Nova e Pedras Altas, na região rural do município baiano de Riachão do Jacuípe. Lembro que o Projeto acena para o respeito às comunidades do campo e traz em seu bojo a defesa da qualidade de vida e de afirmação desta identidade. Como os professores lidam, portanto, com o caráter fluido das identidades no interior de um projeto que investe na afirmação de identidades específicas? Proponho uma abordagem do texto na sala de aula, em sua natureza dialógica, a partir da qual o professor se disponha a considerar os modos de referenciar a realidade e as experiências cotidianas nas produções dos alunos, identificando os possíveis diálogos interculturais na comunidade escolar. Pensar nas identidades exige um exercício de interpretação das experiências vividas e de compreensão da natureza das identidades que se constroem diariamente, não são prontas, homogêneas, não se completam, mas estão em constante construção, já que em diálogo.

Nas produções a seguir, acerca da história de uma das comunidades, é possível identificar os modos de referenciar o cotidiano e tecer algumas considerações sobre em que estes modos dialogam com outras possíveis identidades, além dos elementos da cultura local que são bem enfatizados na grande maioria das produções escolares analisadas. Ressalto que as produções referem-se à sala de aula que é multisseriada, daí a produção se apresentar para turma de Alfabetização ( $1^{\circ}$ ano $)$ e $3^{\text {a }}$ série $\left(4^{\circ}\right.$ ano). Ressalto, ainda, que este exercício de leitura que proponho ocorre pelo fato de a produção ter sido socializada nas paredes da sala, como versão final, sem terem sido feitas considerações a que me proponho fazer e que dariam conta de iniciar um trabalho de letramento escolar que colocasse em pauta questões identitárias. 


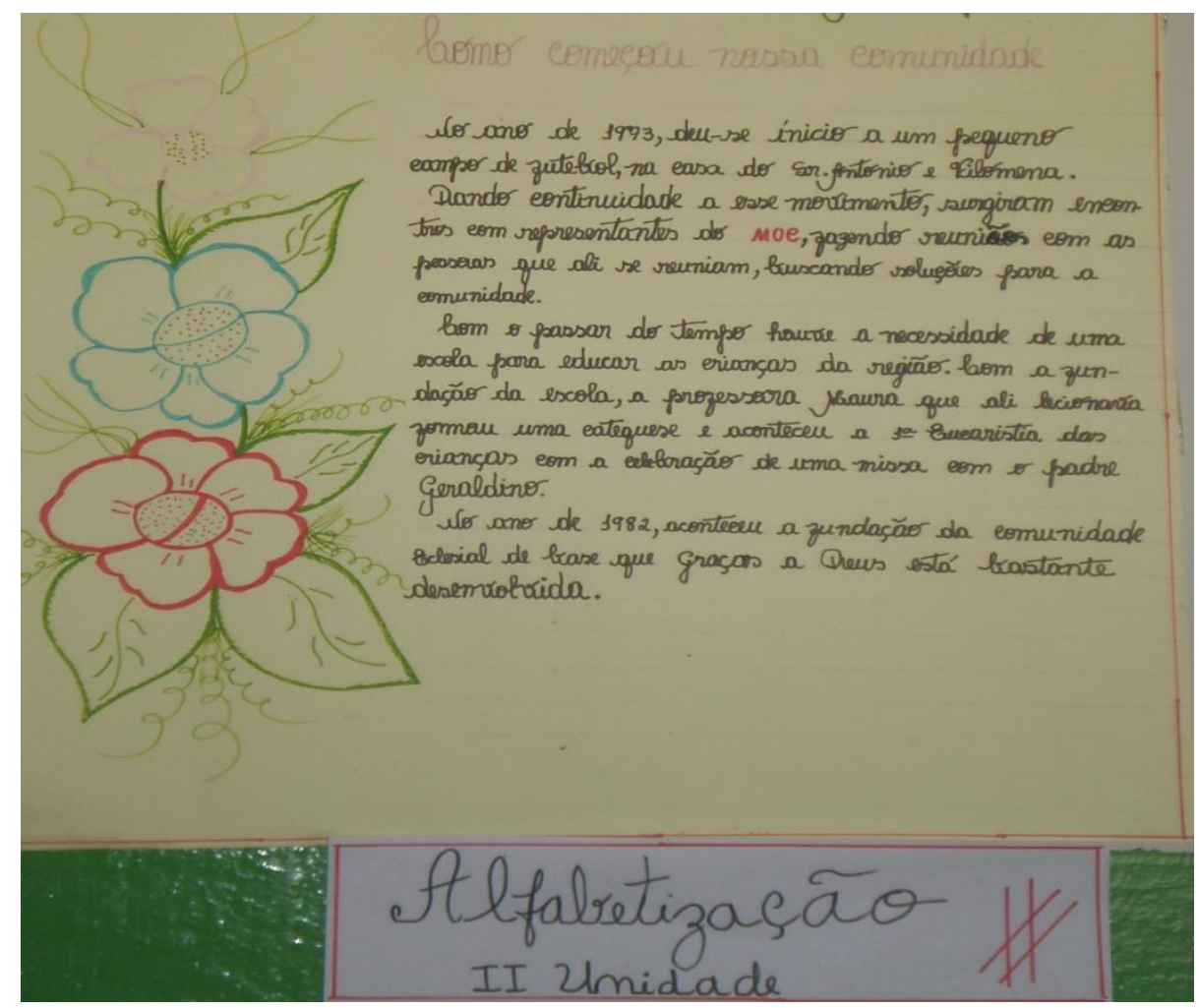

Proponho, então, um exercício de leitura das produções afixadas nas paredes das duas escolas pesquisadas, espaço de divulgação das produções realizadas em sala coletivamente. Este exercício possibilita reflexões sobre como considerar a leitura e a produção na sala de aula, considerando elementos interculturais os quais contribuem para a constituição de identidades. A princípio, o tema é a história local da comunidade, na qual são referidos aspectos importantes que são responsáveis pela fundação do lugar descrito/narrado. O lazer, representado pelo campo de futebol e por um bar, além da educação e da religião, representada pela presença do espaço escolar para a catequese, são os aspectos destacados como responsáveis pela construção da comunidade.

Um olhar pouco atento e crítico consideraria esta superfície textual como satisfatória para o trabalho com texto na escola, bem como para dar conta da temática proposta em sala. No entanto, numa abordagem que considere o caráter dialógico do texto e das práticas de letramento em geral, a discussão seria colocada no plano de um contínuo das produções em rede e outras considerações seriam feitas. A produção foi exposta no mural da sala da Escola M.J.L.C., em Riachão do Jacuípe/BA. 


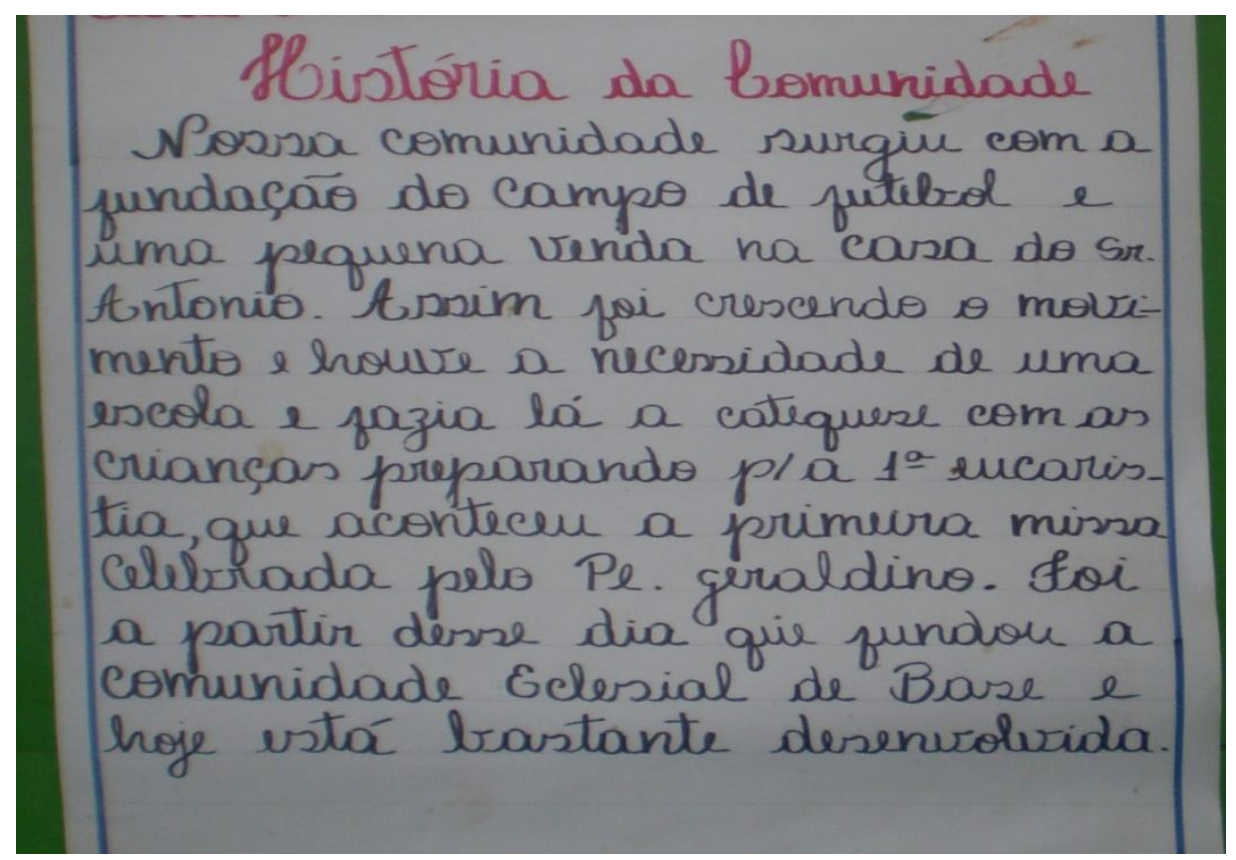

Um primeiro ponto a destacar é sobre a relação escola, religião e lazer. Uma prática voltada para as relações interculturais e identitárias precisa perguntar até que ponto estas relações são superficiais, bem resolvidas, em que nível são estáveis/instáveis, a quais dimensões de poder estão vinculadas. Uma comunidade que se origina neste tripé, tendo uma escola que se inicia com formação catequética e numa religião específica precisa se perguntar sobre a natureza de sua formação identitária. Desta forma, os professores começam a instituir um espaço de leitura do texto em rede, convocando outros textos, de outros espaços para a sala de aula. Esta abordagem questiona a (não) autoria das produções, suas fontes que serviram de base para a consideração de 'verdades' sobre a comunidade, o cotidiano e suas práticas estão também como textos a serem lidos em suas relações mais sutis.

A natureza do Projeto CAT exige um olhar para a cultura local e sua valorização, exige um comprometimento com as experiências cotidianas, com as relações políticas de valorização do campo e desafia a realização de ações que reivindiquem a valorização das comunidades. Que leituras, então, favorecem a reflexão e o senso crítico dos sujeitos envolvidos neste contexto? O espaço escolar, se em diálogo com a sociedade e atento às forças centrípetas e centrífugas que o orientam, consegue pelo menos compreender seus limites e o modo como as identidades diversas circulam pelo cotidiano e favorecem ou desfavorecem as relações na e fora da escola. 
Neste contexto em que desenvolvo a pesquisa acerca dos modos de ler e escrever como práticas de produção de conhecimento e transformação sociocultural, discuto o papel destas práticas com leitura e escrita nas três atividades que sustentam as práticas docentes: de conhecimento da realidade, de análise e de transformação social. As ações estão concentradas na orientação dos princípios expressos no nome do Projeto que se concretizam na construção das fichas pedagógicas de cada unidade de aula. Na sala de aula, os professores colocam em execução as fichas, sempre partindo do conhecimento do cotidiano dos alunos até sua análise e proposta de transformação, daí o tema das produções estar sempre voltado para a cultura e a história locais.

Nesse contexto, comecei a refletir sobre a natureza do texto escrito, considerando inclusive a visão das práticas escriturísticas ressaltada por Certeau, que coloca o ato de escrever como uma prática mítica "moderna", por sobrepor-se a outros modos de dizer:

Procuro ouvir esses frágeis efeitos de corpo na língua, vozes múltiplas, afastadas pela triunfal conquista da economia que, a partir da "modernidade" (séculos XVII e XVIII), se titularizou sob o nome de escritura. Meu tema é a oralidade, mas modificada por três ou quatro séculos de trabalho ocidental. (CERTEAU, 2008a:221-222)

O modo de conceber a escritura por De Certeau me fez pensar sobre como o cotidiano foi sendo escriturado na escola e como a abordagem do letramento escolar dá conta disso. O que da história local veio para a escola? Que questões identitárias são colocadas em discussão no momento do 'conhecer' e do 'analisar' previstos nas fichas pedagógicas, especificamente, referentes ao trabalho com texto?

$\mathrm{Na}$ outra produção a seguir, também exposta na escola, aparece em destaque a preocupação com o tema da identidade, vista em três dimensões: pessoal, familiar e local. Dessa forma, é possível considerar que a escola não tem a clareza de que identidades cambiantes estão em diálogo e que não dá para defender uma identidade uma, bem definida, demarcada nestes níveis que, no máximo, atingem a comunidade local. 


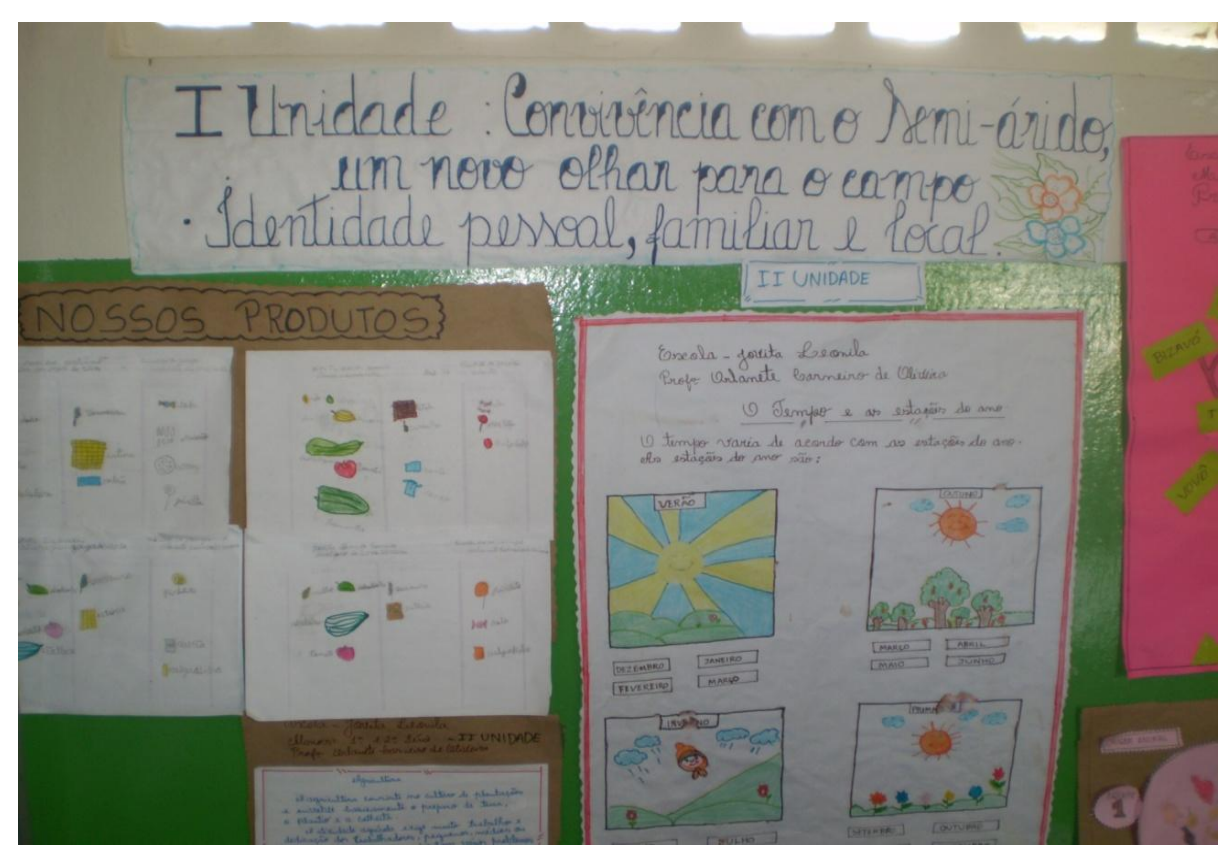

Pela própria disposição das produções no painel, tem-se do lado esquerdo os produtos locais e do lado direito a relação entre tempo e estações do ano, algo universal que interfere na vida local. Mas em que dimensão a escola dá conta dessa realidade e discute os modos de referenciar esta cultura local que transversalmente constitui os sujeitos, suas referências de ser ou não do campo, da caatinga, de ser do Brasil e ocupar uma dita posição na economia mundial?

$\mathrm{Na}$ produção sobre a profissão dos pais e a que sonham em ter quando crescerem, os alunos desenharam e escreveram suas representações cotidianas da vida de seus pais, bem como seus sonhos e representações do eu queriam ser quando crescer. As produções foram socializadas, mas o interessante é observar que profissões dos pais se colocam como modelo para o futuro dos filhos e quais advindas de outras relações interferem nestas decisões e escolhas. 


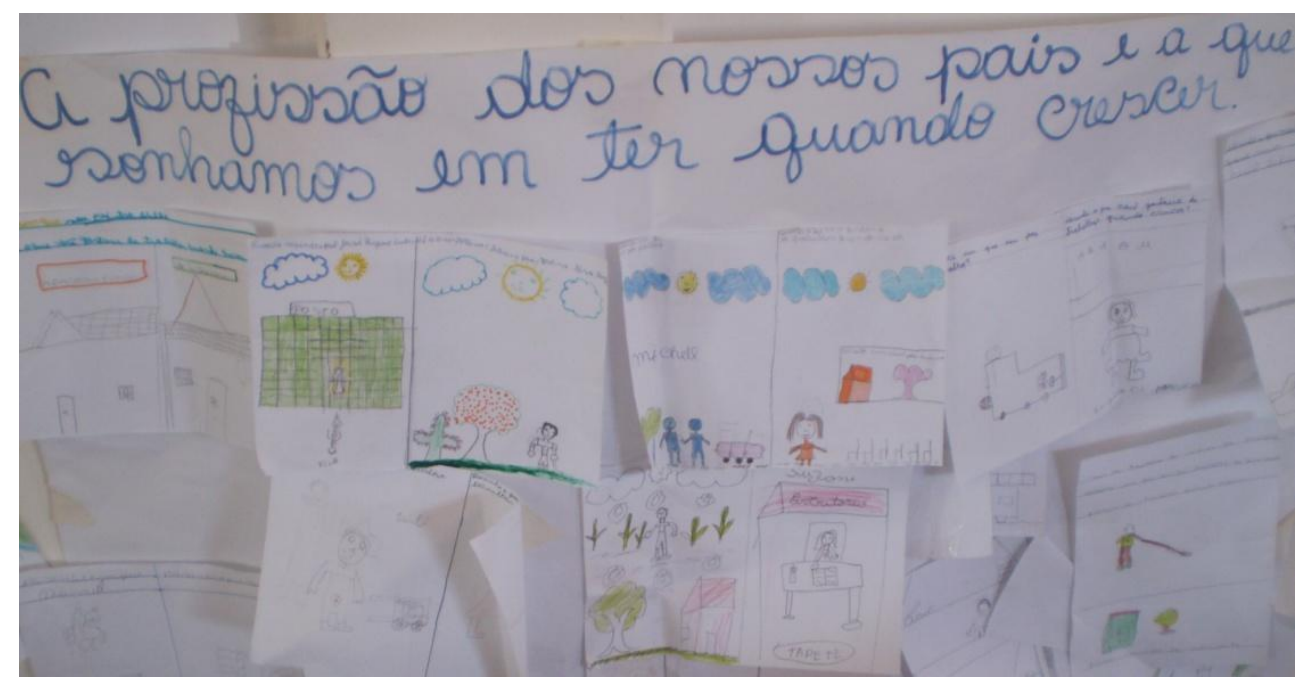

$\mathrm{Na}$ produção ao centro e abaixo, lê-se o título sombreado em vermelho: "Escritório", a baixo do título uma menina sentada a uma mesa e abaixo um desenho com a identificação "Tapete". Do lado esquerdo desta produção está a representação da profissão dos pais, plantações de milho/feijão. Tomo os elementos referencias 'escritório' e 'tapete' para discussão em confronto com a imagem do plantio à sua esquerda. São representações, escrituras de um cotidiano vivenciado em família e de um cotidiano idealizado para si futuramente. Que fatores culturais e identitários interferem nestas escolhas? Como são lidas estas produções e seus elementos referenciais? Escritório e tapete estão num campo referencial diferenciado do campo referencial do plantio, exigindo conhecimentos e valores socais diferenciados. O que o letramento escolar possibilita discutir a partir deste confronto de lugares na comunidade? Como possibilita que estas escolhas circulem e façam sentido? Como são interpretadas estas representações? São questões identitárias, fluidas, cambiantes como defende Hall (2006) e que afetam os modos de letrar os sujeitos.

\section{CONCLUSÂO}

Meu tema de estudo vem sendo as práticas com texto, ampliando-se para textos de natureza multimodal, nos espaços diversos de letramento. Para este artigo, propus uma reflexão sobre a relação entre letramento escolar e identidade, mostrando através de um breve exercício de leitura, como podem ser lidas as relações cotidianas e a 
constituição de identidades nos textos, considerados em rede, no interior das atividades docentes. Este exercício forneceu elementos teóricos e metodológicos sobre como o texto pode ser tratado na sala de aula. Teoricamente, este exercício possibilitou a ênfase numa noção de texto que, ainda que seja considerado em sua forma escrita, ele funciona em rede na sociedade, dialogando com outros textos, inclusive com as práticas cotidianas que configuram a cultura local em diálogo com outras não-locais. Metodologicamente, repercute nas práticas docentes que interpretam textos considerando exclusivamente seus elementos formais e superficiais, mostrando como a consideração de elementos referenciais pode ser gerador de outros modos de ler o cotidiano, transcendendo as escrituras.

Quando se toma o texto como objeto de estudo e de trabalho docente, há necessidade de se dialogar com noções teóricas de natureza interdisciplinar, pois trata-se de espaço complexo, que requer olhar para elementos diferenciados e que não são exclusivamente da ordem do linguístico, mas que se colocam em proximidade constitutiva de conhecimentos diversos. Daí a convocação de referenciais da Linguística do Texto, dos Estudos Discursivos e dos Gêneros de Discurso, além de noções centrais nos Estudos Culturais. Esta configuração de noções vem contribuindo para o amadurecimento de meu modo de conceber o texto e as escrituras tanto em espaço escolar como em outros espaços sociais, mas que também são de formação docente ou, pelo menos, dão elementos para sua redefinição.

Não escolhi descrever ações de sala de aula, mas me coloquei numa ação de ler textos em circulação nas duas escolas nas quais venho pesquisando, como uma forma de mobilizar uma categoria que considero extremamente importante para a comunhão de aspectos formais do texto com aspectos do cotidiano, que são escriturados na escola: a categoria referencial. Defendo esta categoria como indiciária das relações dialógicas, das representações do cotidiano, das configurações identitárias e culturais. O letramento escolar, portanto, não pode nem deve suprimir de suas práticas os modos de referenciar os sujeitos e sua(s) identidade(s) e cultura(s), relegando seus princípios norteadores de conhecimento e análise da realidade, bem como de seus espaços de reflexão sobre as possíveis ações de transformação social, a partir do momento que se coloca numa posição de escriturária da realidade circundante. 


\section{REFERÊNCIAS}

BAKHTIN, Mikhail (1895-1975). Estética da criação verbal. 2' cd. São Paulo: Martins Fontes, 1997.

BAKHTIN, Mikhail. Marxismo e filosofia da linguagem. São Paulo: Hucitec, 2004.

DE CERTEAU, Michel. A invenção do cotidiano: 1 Artes de fazer. 14 ed. Petrópolis, RJ: Vozes, 2008a.

DE CERTEAU, Michel. A invenção do cotidiano: 2 Morar, cozinhar. 7 ed. Petrópolis, RJ: Vozes, 2008b.

FREIRE, Paulo. A importância do ato de ler: em três artigos que se completam. São Paulo: Cortez, 1989.

FREIRE, Paulo. Ação cultural para a liberdade. Rio de Janeiro: Paz e Terra, 1981.

FREIRE, Paulo. Educação e mudança. São Paulo: Paz e Terra, 12ª edição, 1979.

HALL, Stuart. Da diáspora: identidades e mediações culturais. Belo Horizonte: Editora da UFMG, 2003.

KLEIMAN, Ângela. Os significados do letramento: uma nova perspective sobre a prática social escrita. Campina, SP: Mercado de Letras, 2003[1995].

STREET, Brian V. Literacy in theory and practice. (Cambridge studies in oral and literate culture). Cabridige University Press, 1984.

RECEBIDO EM: 01 de novembro de 2012

APROVADO EM: 05 de dezembro de 2012 